\title{
Transport service of a cargo consolidation centre with respect to logistics service of urban agglomerations
}

\author{
D. Pyza \\ Warsaw University of Technology Faculty of Transport, Poland
}

\begin{abstract}
In the paper, a solution to a distribution system in an urban agglomeration, in which the transport service is performed by a Cargo Consolidation Centre (CCC), is presented. The model proposed in the paper aims at reducing cargo traffic in the urban area by coordinating traffic flows and eliminating empty runs. After reviewing the issues relating to distribution systems with reference to urban logistics, later in the article a mathematical approach to the supply problem was identified. Therefore, the formalization of input data, constraints, and criterion function notation was performed. On this basis, an optimization task for the distribution of goods in the urban agglomeration was formed. The final component of the paper is the presentation of solutions to the analysed case study, in which the problem was solved with the use of computer-aided methods. Keywords: urban logistics, distribution system, transportation system, optimization, computer-aided methods and tools.
\end{abstract}

\section{Introduction}

The subject of the research is the implementation of services connected with the flow of goods in urban areas and the miscellaneous information streams related to them. For the purpose of service delivery at an appropriate level and a smooth movement of cargo, it is necessary to integrate the physical flow of goods and related information within a well-functioning Urban Logistics System (ULS). Cargo transportation is, on the one hand, the major factor enabling the economic and social development of urban areas, and, on the other hand, it is the major source of environmental pollution, as well as impeding the social life of urban residents. Solutions to prevent this phenomenon should, therefore, be seen in 
urban logistics, whose task is to coordinate, organize and manage the flows of resources between urban logistics subsystems, with a particular focus on the efficiency of cargo flows and, consequently, the restriction of cargo traffic in cities.

\section{Transport in urban logistics system}

The adaptation of the systems theory for urban logistics allows a system's approach to be adopted that enables the rationalization of the urban logistics system for the situation when every component of the system will be subordinated to the overall objective, and its performance is evaluated in terms of the rationalization of global tasks. Consequently, this approach means the elimination of suboptimization of the solution, as individual components of the system seek such forms of cooperation that are required in all parts of the logistics system seen as a whole [9]. Thus, the city constitutes a specific system object within which various subsystems comprising of specific organisational units can be isolated. The operation of an urban logistic system determines the occurrence of the many logistics processes in it, which may include, among others, the procurement, production and goods distribution processes, as well as processes of the transportation of cargo and people and of information flow. In addition, storage processes and ecological processes - recycling and waste treatment (Fig. 1) are among the significant logistics processes implemented in the urban logistics system.

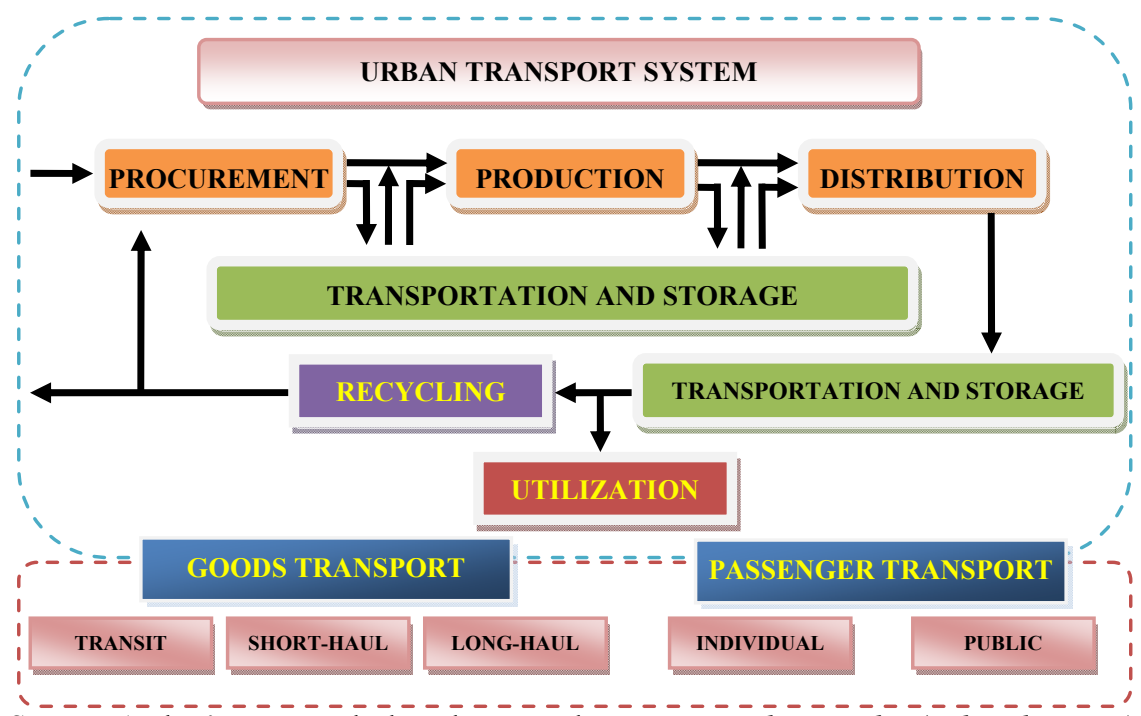

Source: Author's own study based on Tundys B., Logistyka miejska (Urban logistics), Centrum doradztwa i Informacji Difin, Warszawa 2008.

Figure 1: Logistics processes in an urban logistics system. 
When considering a city as a logistics system, an important element is the impact of logistics chains running through the city. The efficiency of urban logistics chains, in a sense, is a determinant of the efficiency of the city itself and its management system. In terms of urban logistics rules, the transportation system, which through links has an impact on all other urban subsystems plays the most important role in the logistics chain. Only an effective, efficient, accessible and functional transportation system allows all urban functions to be performed and satisfies the needs of other subsystems. Transport is a component that integrates the city in terms of the functional system and presents an urban centre as a system of interdependences occurring between its particular components. An efficient urban transport system should be matched to the size, character and spatial diversity of transportation needs in the given area, allowing the performance of functions fulfilled by the city. When considering the implementation of internal flows in the city, one can distinguish the transportation of cargo and people and disposal of waste and rubbish. The structure of transport services performed in urban agglomerations indicates that the goods transport and passenger transport account for one third and two third of all transport services, respectively. Urban cargo transport is associated with the delivery transport, by which is generally meant cargo transport for and within the city, as well as for the whole urban area, covering mainly the services sector, as well as transport for production plants. In general, the urban cargo transport can be divided into [6]:

- long-haul transport - inbound/outbound;

- short-haul transport - intraurban;

- transit transport - running through the city and having no destinations in the city.

The biggest part of cargo is transported by road, the largest percentage of which is transported by car. The structure and size of the transportation volume depend on the type of cargo group, functional area, cargo amount, transport distances and types of means of transport. The above-mentioned determinants are variable and depend on the industry, company financial performance and applied solutions in the field of the transport service of supply chains. The smooth functioning of the transport processes in the urban area is affected by the infrastructure, which includes, among others, roads and streets along with their technical equipment and places of transhipment, and moreover by the suprastructure and means of transport, which include various types of vehicles, installations and equipment for the efficient organization of loading, transportation and unloading. Thus, in this aspect, the goods transport should be integrated, determining the smooth flow of cargo to destinations in the city and of cargo passing in transit, as well as the reception of goods from their manufacturers, and the export of them outside the city boundaries. The problems that exist in the transport of goods in the city are very diverse and have many sources of origin. One of them is the occurrence of congestion, which is to be understood as the appearance of a bigger number of purchasers and users of e.g. means of transport or a transport network at the same time and in the same place. 
Thus, considering the transport congestion, one can speak about the congestion of the transport network and the congestion in means of transport. Another problem we face in the transport of goods in the city is the utilization rate of means of transport, where, if they are used only partially, empty runs occur. Problems connected with transport in the city, which are indicated by transport companies are also long journeys through the city, waiting in traffic jams on the crowded streets and the lack of parking spaces at the cargo receiving points.

\section{Cargo consolidation centres as an element improving flow of goods in the city}

The negative effects of transport processes in the city require appropriate solutions to remedy them. A reduction in cargo transport is possible by undertaking infrastructural, organisational or legal measures. Solving transport problems connected with supplying shops, cleaning the city or transit should include the rules of urban logistics and its implications to allow the coordination of cargo movement in time and space by means of transport, as well as the application of transport organisation systems and solutions through the consolidation of cargo transport within urban areas based on urban terminals or logistic centers. There are also important legal and organisational measures for effectively solving urban transport problems. These measures may include: reducing the delivery time span for designated urban areas, establishing limited traffic zones or implementing a night delivery system. One of the major components for solving the problems of the transport of goods in the city is the good organization of transport chains, which means the designation of points linking individual systems to achieve economies of scale and a synergistic effect within a limited city area. For this purpose, we use transport optimization methods and tools by formulating appropriate optimization tasks and then solving them. Optimising the flow of goods in the city is aimed at reducing the length of time that a vehicle is in the city, the number and length of routes, as well as the better utilization of the loading space of the means of transport. In the paper, a single-criterion optimization task is formulated for a one-stage goods distribution system in the urban agglomeration, which takes into account the above-mentioned optimization aspects.

Assuming the city is a starting point for logistics activities, the subject of operations in its area specifying in detail the scope of urban logistics will be areas connected with [11]:

- transportation of cargo in the city - delivery, inbound and outbound transport, and transit transport, and the creation of transport links between agglomerations and the macro-regional logistics system;

- protection and storage of goods meeting the needs of the city.

The organisation of cargo transport in the city is related to intraurban transport, transport to and from the city, and transit through the city. Goods transport is essential for the functioning of supply chains, which develop in the city between its functional zones, as well as for those which cover a wider area and whose only segment located in the city is the first, last or any other segment. 
The organisation of cargo transport is closely connected with the development of the transport links of the city and agglomeration with the macro-regional logistics system. Protecting and storing the goods that meet the needs of the city is connected with the assignment of land within the city boundaries or its precincts for the construction of storage places, warehousing centres, distribution centres or city terminals. One of the conceptions that aims at relieving the city of excessive goods traffic is the infrastructural solution based on building logistics centres and cargo transhipment and consolidation places - City Terminals. The logistics centre brings relief to the city and helps it to get rid of the goods transport carried out by means of transport with large load capacities as the city centre area constitutes a sort of "stop" for goods, carried by both short-haul and long-haul transport [6]. Another solution is City Terminals, where the coordination of goods flows in the city is effected in order to combine shipments of specified goods gravitating towards the city centre area at one or more centrally located distribution terminals. In addition, the urban terminals can be used as a so-called "gateway" for the city supply system. To a limited extent, they can serve as cargo consolidation centres for all transport streams flowing through the city. At the same time, in the absence of a logistics centre, they can directly be used to serve the long-haul transport and be regarded as the cargo consolidation centres.

\section{The problem of a distribution system in urban area: mathematical formalization of the problem}

The optimization task of the transport service in a one-stage goods distribution system in the urban agglomeration is formulated as follows. There is a distinguished set $\boldsymbol{O}=\left\{o^{i}: i=\overline{0, I}\right\}$ of numbers of places where there is the demand for goods (customers) and a cargo consolidation centre (CCC), from which customers are served. The goods receiving places are characterised by the size of interpreted customer demand for the type- $r^{k}$ goods $\boldsymbol{R}=\left\{r^{k}: k=\overline{1, K}\right\}$, presented in the form of the matrix $\Psi=\left[\psi\left(o^{i}, r^{k}\right) \equiv \psi_{o^{i}}^{r^{k}} \in \mathfrak{R}^{+}: o^{i} \in \boldsymbol{O}, r^{k} \in \boldsymbol{R}, i \neq 0\right]_{I \times K}$. The transport service of the distribution system is provided by a logistics operator supplying transport services, who has at his disposal the set $\boldsymbol{P}=\left\{p^{n}: n=\overline{1, N}\right\}$ of means of transport numbers. Each means of transport being at the disposal of the logistics operator is characterised by loading capacity $q\left(p^{n}\right) \equiv q_{p^{n}} \in \mathfrak{R}^{+}: p^{n} \in \boldsymbol{P}$ and volume $g\left(p^{n}\right) \equiv g_{p^{n}} \in \mathfrak{R}^{+}: p^{n} \in \boldsymbol{P}$. The goods delivered to customers (receiving points) are collected from the cargo consolidation centre (CCC) within a predetermined time window written as $\Phi(C K L) \equiv \Phi_{C K L}=\left\langle\varphi^{\prime}(C K L), \varphi^{\prime \prime}(C K L)\right\rangle ; \varphi^{\prime}(C K L) \in \mathfrak{R}^{+}, \varphi^{\prime \prime}(C K L) \in \mathfrak{R}^{+}$.

In 
addition, the fulfilment of orders compels the operator to make deliveries within strictly defined time spans $T\left(o^{i}, p^{n}\right) \equiv T_{o^{i}}^{p^{n}}=\left\langle t^{\prime}\left(o^{i}, p^{n}\right), t^{\prime \prime}\left(o^{i}, p^{n}\right) \equiv t_{o^{i}}^{p^{n}}, t_{o^{i}}^{p^{n}}\right\rangle ; t_{o^{i}}^{p^{n}} \in \mathfrak{R}^{+}, t_{o^{i}}^{p^{n}} \in \mathfrak{R}^{+}$, in which the service must begin/end, delivery times can be the same for all customers or different as a result of customer preferences.

The additional assumptions for the one-stage distribution system are as follows:

- the loading time $\delta 1\left(p^{n}, o^{i}\right) \equiv \delta 1_{p^{n}}^{o^{i}}, \quad p^{n} \in \boldsymbol{P}, \quad o^{i} \in \boldsymbol{O}$ and unloading time $\delta 2\left(p^{n}, o^{i}\right) \equiv \delta 2_{p^{n}}^{o^{i}}, p^{n} \in \boldsymbol{P}, o^{i} \in \boldsymbol{O}$ of the $p^{n}$-th means of transport;

- direct connection distances between goods receiving points and $\mathrm{CCC}$, written as $\quad \mathrm{D}=\left[d\left(o^{i}, o^{j}\right) \equiv d_{o^{i} o^{j}} \in \mathfrak{R}^{+}, i, j \in \boldsymbol{O}\right]_{(I+1) \times(I+1)}, \quad$ mean driving speed $v\left(p^{n}\right) \equiv v_{p^{n}} \in \mathfrak{R}^{+}: p^{n} \in \boldsymbol{P}$ and travel time $\delta 3\left(o^{i}, o^{j}, p^{n}\right) \equiv \delta 3_{o^{i} o^{j}}^{p^{n}}$ between goods receiving points and $\mathrm{CCC}$;

- the cost $\kappa\left(p^{n}\right) \equiv \kappa_{p^{n}} \in \mathfrak{R}^{+}: p^{n} \in \boldsymbol{P}$ of one kilometre covered by the $p^{n}$-th means of transport;

- the moment $\varepsilon_{o^{0}}^{p^{n}}$ of departure of the $p^{n}$-th means of transport from CCC and the moment of departure $\varepsilon_{o^{i}}^{p^{n}}$ of the $p^{n}$-th means of transport from the $o^{i}$-th receiving point.

For such written data, one needs to determine such values of the decision variable $x_{o^{i}, o^{j}}^{p^{n}}$, where: $x_{o^{i}, o^{j}}^{p^{n}}=1$ for $o^{i} \in \boldsymbol{O}, o^{j} \in \boldsymbol{O}, p^{n} \in \boldsymbol{P}-$ when $\left(o^{i}, o^{j}\right)$ is contained in the route of the $p^{n}$-th means of transport, 0 , otherwise meeting the constraints:

$$
\begin{gathered}
\sum_{o^{i}: i=0}^{I} \sum_{p^{n}: n=1}^{N} x_{o^{i} o^{j}}^{p^{n}}=1, \forall o^{j}: j=\overline{0, I} \\
\sum_{o^{j}: j=0}^{I} \sum_{p^{n}: n=1}^{N} x_{o^{i} o^{j}}^{p^{n}}=1, \forall o^{i}: i=\overline{0, I} \\
\sum_{o^{i}: i=0}^{I} x_{o^{i} o^{w}}^{p^{n}}-\sum_{o^{j}: j=1}^{I} x_{o^{w} o^{j}}^{p^{n}}=1, \forall p^{n}: n=\overline{0, N} ; \forall o^{w}: w=\overline{0, I} \\
\sum_{o^{i}: i=0}^{I} \sum_{r^{k}: k=1}^{K} b_{o^{i}}^{r^{k}} \cdot \sum_{o^{j}: j=1}^{I} x_{o^{i} o^{j}}^{p^{n}} \leq q_{p^{n}}, \forall p^{n}: n=\overline{0, N} ; \forall r^{k}: k=\overline{0, K} \\
\sum_{o^{i}: i=0}^{I} \sum_{r^{k}: k=1}^{K} b_{o^{i}}^{r^{k}} \cdot \sum_{o^{j}: j=1}^{I} x_{o^{i} o^{j}}^{p^{n}} \leq g_{p^{n}}, \forall p^{n}: n=\overline{0, N} ; \forall r^{k}: k=\overline{0, K} ; \\
\sum_{o^{i}: i=0}^{I} \delta 1_{o^{i}}^{p^{m}} \cdot \sum_{o^{j}: j=1}^{I} x_{o^{i} o^{j}}^{p^{n}}+\sum_{o^{i}: i=0}^{I} \sum_{o^{j}: j=0}^{I} \delta 3_{o^{i} o^{j}}^{p^{n}} x_{o^{i} o^{j}}^{p^{n}} \leq T_{p^{n}}, \forall p^{n}: n=\overline{0, N}
\end{gathered}
$$




$$
\begin{gathered}
z_{o^{i}}-z_{o^{j}}+I \cdot \sum_{p^{n}: n=1}^{N} x_{o^{i} o^{j}}^{p^{n}} \leq I-1,0 \leq o^{i} \neq o^{j} \leq I, \quad z_{o^{i}}, z_{o^{j}} \in \mathfrak{R}^{+} \\
x_{o^{i} o^{j}}^{p^{n}} \in\{0,1\}, i, j=\overline{0, I}, \quad n=\overline{0, N} \\
\varepsilon_{o^{j}}^{p^{n}}=x_{o^{i} o^{j}}^{p^{n}} \cdot \max \left\{\varepsilon_{o^{i}}^{p^{n}}+\delta 3_{o^{i} o^{j}}^{p^{n}}, t_{o^{j}}^{p^{n}}\right\}+\delta 2_{p^{n}}^{o^{j}}, i, j=\overline{0, I}, \forall p^{n}: n=\overline{0, N} \\
\varepsilon_{o^{0}}^{p^{n}} \geq t_{o^{0}}^{p^{n}}, \forall p^{n}: n=\overline{0, N} \\
t_{o^{i}}^{p^{n}} \leq \varepsilon_{o^{i}}^{p^{n}}-\delta 1_{p^{n}}^{o^{i}} \leq t_{o^{i}}^{p^{n}}, \forall o^{i}: i=\overline{0, I}, \forall p^{n}: n=\overline{0, N}
\end{gathered}
$$

which condition the minimum costs of transportation to customers, written as:

$$
f(X)=\sum_{o^{i}: i=0}^{I} \sum_{o^{j}: j=0}^{I} \sum_{p^{n}: n=0}^{N} d_{o^{i} o^{j}} x_{o^{i} o^{j}}^{p^{n}} \kappa_{p^{n}}
$$

\section{Case study of a one-stage distribution system for urban agglomeration}

The optimization methodology of transportation services for the urban agglomeration, which is presented in Section 4 was verified taking as an instance the cargo consolidation centre in Błonie (Fig. 2), which supports 50 receiving points located throughout the city of Warsaw.

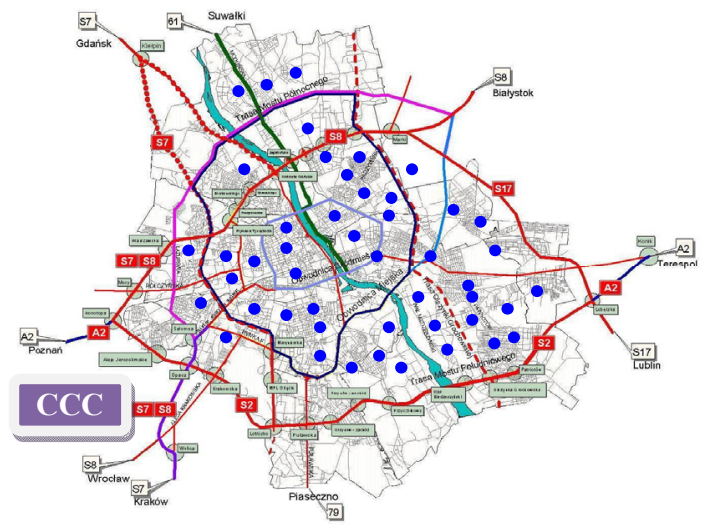

Source: Author's own study.

Figure 2: Area covered by the transport network of the cargo consolidation centre.

The optimization of transportation services for the investigated cargo consolidation centre consists in choosing a transportation organization so as to achieve the minimum cost of performing transport tasks. The analysis was performed with respect to one working day of the transport company. After 
Table 1: $\quad$ Service points and the size of their demand (demand table section).

\begin{tabular}{cccccc} 
Item & \multicolumn{2}{c}{$\begin{array}{c}\text { Demand size of company } \\
\text { receiving points }\end{array}$} & Item & \multicolumn{2}{c}{$\begin{array}{c}\text { Demand size of company } \\
\text { receiving points }\end{array}$} \\
& $k g$ & $p c u *$ & & $k g$ & $p c u^{*}$ \\
1 & 482 & 6 & 26 & 42 & 1 \\
2 & 228 & 2 & 27 & 126 & 2 \\
$\ldots$ & $\ldots$ & $\ldots$ & $\ldots$ & $\ldots$ & $\ldots$ \\
25 & 194 & 4 & 50 & 151 & 2 \\
\hline
\end{tabular}

* pallet cargo unit

Source: Author's own study based on company-provided data.

remaining days of the year can be determined by analogy. Demand sizes of cargo receiving points are compiled in Table 1.

The logistics operator has five means of transport at its disposal: $p^{1}-$ Iveco Turbo Daile (loading capacity 3,500 kg); $p^{2}$ - Renault S120 (loading capacity $3,500 \mathrm{~kg}) ; p^{3}$ - Renault Master (loading capacity 1,500 kg); $p^{4}$ - Renault Midlum (loading capacity 6,800 kg); $p^{5}-$ Star 742 (loading capacity 3,000 kg).

In Table 2, travel times between receiving points are compiled, assuming an average driving speed of $50 \mathrm{~km} / \mathrm{h}$.

Table 2: $\quad$ Travel times between receiving points (table section).

\begin{tabular}{|c|c|c|c|c|c|c|c|c|c|}
\hline \multicolumn{10}{|c|}{ Numbers of receiving points } \\
\hline \multirow{6}{*}{ 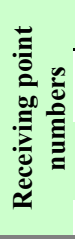 } & & $\mathbf{0}$ & 1 & 2 & 3 & 4 & 5 & $\ldots$ & 50 \\
\hline & 0 & ------ & 41 & 44 & 43 & 44 & 40 & $\ldots$ & 51 \\
\hline & 1 & & ------ & 5 & 5 & 6 & 3 & $\ldots$. & 12 \\
\hline & 2 & & & ------ & 2 & 5 & 8 & $\cdots$ & 14 \\
\hline & .... & & & & & & & $\ldots$ & 14 \\
\hline & 50 & & & & & & & & ------ \\
\hline
\end{tabular}

Source: Author's own study.

Service times at CCC and receiving points amount to 20 minutes in each case. Delivery time spans amount to 12 hours from 6 a.m. to 6 p.m. As an optimization tool, the software Optimization of outbound transport routes was used. The software constitutes an essential element in the decision-making process concerning cargo distribution. For the optimization, the random resource allocation method backed by the evolutionary method with a limited set of genetic algorithms allowing for directed task improvement is employed. Thus, theoretically, the result is the best itinerary of the set of allowable itineraries. However, practically, for a set size ranging from10 to 100 million tested itineraries, the best itinerary selected can be regarded as optimal. As a result of solving an appropriately formulated optimization task using the software, the following results were obtained.

The longest route is operated by means of transport No. 1, while the shortest one by means of transport No. 5. Route length covered by the means of transport determines transportation costs as well as their utilization rate. 


\section{Routes covered by individual means of transport during one day}

Means of transport No. 1:<0, 26, 46, 10, 33, 50, 27, 8, 1, 6, 43, 12, 24, 14, $0>$

Means of transport No. 2: $<0,25,9,5,23,18,39,37,11,48,16,32,40,45$, $28,36,31,0>$

Means of transport No. 3: $<0,42,0>$

Means of transport No. 4: $<0,22,47,42,34,2,4,38,41,49,3,7,31,13,20$, $15,19,35,30,0>$

Means of transport No. 5: $<0,44,0>$

\section{Daily route lengths covered by each individual means of transport:}

\begin{tabular}{lr|}
\hline Means of transport No 1: & $228,3 \mathrm{~km}$ \\
\hline Means of transport No 2: & $225,2 \mathrm{~km}$ \\
\hline Means of transport No 3: & $47,6 \mathrm{~km}$ \\
Means of transport No 4: & $209,3 \mathrm{~km}$ \\
\hline Means of transport No 5: & $29,6 \mathrm{~km}$ \\
Total: & $\mathbf{7 1 0 , 4} \mathbf{~ k m}$ \\
\hline
\end{tabular}

Source: Author's own study.

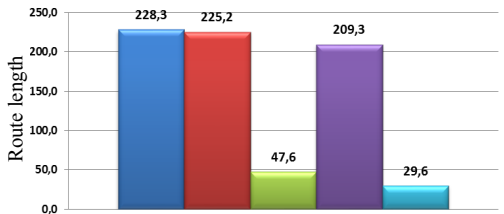

Figure 3: $\quad$ Route lengths covered by means of transport.

\section{Daily transportation costs borne by the logistics operator:}

\begin{tabular}{lr|}
\hline Means of transport No. 1: & $366.20 \mathrm{zl}$ \\
\hline Means of transport No. 2: & $341.10 \mathrm{zl}$ \\
\hline Means of transport No. 3: & $99.96 \mathrm{zl}$ \\
Means of transport No. 4: & $585.20 \mathrm{zl}$ \\
\hline Means of transport No. 5: & $65.12 \mathrm{zl}$ \\
\hline Total: & $\mathbf{1 4 5 7 . 5 8 ~ z l}$ \\
\hline
\end{tabular}

means of transport No. Means of transport No. 3 Means of transport No. Means of trasp ans of transport No. 4

Source: Author's own study.

Figure 4: $\quad$ Transportation costs generated by means of transport.

Among additional (in the formulated problem, it was assumed that the optimization criterion is the performance cost of the logistics task) quantitative indicators of the assessment of the transport service provided in the investigated distribution system, including the cargo consolidation centre for the urban agglomeration, average utilization rate of means of transport and their working time are counted. The utilization rate of means of transport for the analyzed case study is $65 \%$ while the working time 2567 min., which represents a $71.3 \%$ working time utilization per shift. 


\section{Utilization percentage for means of transport providing transportation under the one-stage distribution system:}

Means of transport No. $1-97 \%$, Means of transport No. $2-97 \%$; Means of transport No. 3-18\%; Means of transport No. $4-99 \%$; Means of transport No. $5-12 \%$

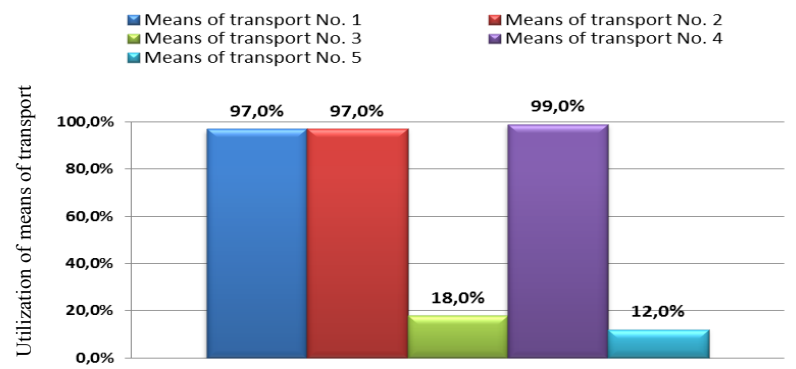

Source: Author's own study.

Figure 5: Utilization percentage for means of transport.

\section{Conclusions}

Goods intended for sale must reach the retail selling point and be offered to the consumer in the right quantity, right quality, in the right place at the right time and at costs acceptable to the customer. Goods distribution, particularly in urban agglomerations, must fulfil two basic functions: organizational and coordinative. The coordinating role is to overcome disparities between supply and demand for a given product with respect to time, place, quantity or choice. Implementation of the decisions taken in the coordination process of supply and demand takes place in the course of fulfilling organizational functions, which include such activities as transportation, storage, commercial processing (sorting, packing), conversion of production product range into commercial, sales to dealers and consumers. Through these activities, a physical flow of products from the manufacturer to purchaser takes place, which is called physical distribution or distribution logistics. An important link in the distribution of goods to customers is the logistics operators providing transport services. The customers located in urban agglomeration areas communicating demand for goods have different requirements and expectations towards service providers. They expect them to perform a high level of quality service at an acceptable price.

Thus, there is an optimization problem of transport service provided to the distribution system operating in the urban agglomeration. Problems of this kind can be solved with the use of computer applications, which are a convenient tool for analysing various service organization variants. This procedure requires that the decision-maker be able to formulate an optimization task and then to solve it using software tools. 


\section{Acknowledgement}

The scientific research funded from the state science budget for 2010-2012 as Research Project No. N N509 601939 - Project manager Dr. Eng. Dariusz Pyza.

\section{References}

[1] Całczyński A. "Metody optymalizacyjne w obstudze transportowej rynku” (Optimization methods in market transport services), (OWPW, Warszawa 2001.

[2] Ignasiak E. (red): "Badania operacyjne" (Operational research), Polskie Wydawnictwo Ekonomiczne, Warszawa 2001.

[3] Jacyna M.: "Modelowanie i ocena systemów przewozowych" (Modelling and evaluation of transportation systems), Oficyna Wydawnicza PW, Warszawa 2009.

[4] Krawczyk S.: "Zarzadzanie procesami logistycznymi” (Management of logistics processes), PWE, Warszawa 2001.

[5] Leszczyński J.: "Modelowanie systemów i procesów transportowych" (Modelling of transportation systems and processes), PWE, Warszawa 1994.

[6] Tundys B., Logistyka miejska (Urban logistics), Centrum doradztwa i Informacji Difin, Warszawa 2008.

[7] Jacyna M.: "Multicriteria Evaluation of Traffic Flow Distribution in a Multimodal Transport Corridor", Taking into Account Logistics Base Service Archives of Transport, Polish Academy of Sciences, Com. of Transport, vol. 10 iss.1-2, Warsaw 1999.

[8] Pyza D.: "Optimization of transport in distribution systems with restrictions on delivery times", Archives of Transport, Polish Academy of Sciences Committee of Transport, volume 21, issue 3-4, Warsaw 2009.

[9] Szałek B. Z., Miasto $w$ świetle nowoczesnej logistyki (City in the light of modern logistics), [in:] Gospodarka materiałowa i logistyka $\mathrm{nr}$ 10.1995, Warszawa 1995.

[10] Dariusz Pyza: "Computer-assisted supply chain distribution processes" chapter 7. Monograph - New insights into Supply Chain (ed.) Katarzyna Grzybowska, ISBN 978-83-7143-944-5. Publishing House of Poznań University of Technology, Poland. Poznań 2010.

[11] Szymczak M., O istocie i funkcjach logistyki miejskie (On the nature and functions of urban logistics), [in:] Wspótczesne kierunki rozwoju logistyki red. E. Gołembska, Państwowe Wydawnictwo Ekonomiczne, Warszawa 2006. 